\title{
Value Chain Based Framework for Assessing the Ferdows' Strategic Plant Role: An Empirical Study
}

\author{
M. Mediavilla ${ }^{1}$, Ander Errasti $^{2}$, R. Domingo ${ }^{3}$, and Sandra Martínez ${ }^{2}$ \\ ${ }^{1}$ BSH Home Appliances, Munich, Germany \\ Miguel.Mediavilla@BSHG.COM \\ ${ }^{2}$ Engineering School, Tecnun, University of Navarra, San Sebastián, Spain \\ \{smartinez, aerrasti\} @tecnun.es \\ ${ }^{3}$ Manufacturing Engineering Department, UNED University, Madrid, Spain \\ rdomingo@ind.uned.es
}

\begin{abstract}
In the current global economy, with an increased international presence of all type of organisations, the design and management of global operations networks (GON) plays a vital role in organisational competitiveness. Whilst all type of organisations are facing significant challenges for managing increasingly complex global operation, current literature on global operation networks is still limited in its scope. The aim of this paper is to discuss the development and evaluation of a construct for assessing the strategic plant role and developing of an improvement roadmap in GONs. This research makes a contribution to current knowledge on global operations by extending the model proposed by Ferdows and operationalizing it to enable its application for the design and optimisation of global operations networks.
\end{abstract}

Keywords: Global operations network, strategic factory role, case study.

\section{Introduction}

The internationalization trend among companies, both in sales and manufacturing has been mainly adopted by multinationals, but small-medium sized companies are also forced to go global [1]. Precisely as consequence of the economic globalization, the global operations network (GON) design will increasingly have to cover multiple regions and cope with higher network complexity [2-3], connecting markets to global supply and manufacturing sources beyond any geographical or shareholding border. Anyhow, the literature on global operations containing models to design and restructure GON is scarce and fragmented [1].

An interesting proposal was carried out by Ferdows [4-5], who stated that the management of GON could be executed based on the strategic plant role concept. However, there are few evidences of empirical testing of Ferdows' model and the deployment of the strategic plant role concept to an operational level [6],[22]. As a result, any attempt to design and/or restructure a GON is difficult to put into practice, as the plant role concept is complex to formulate, deploy and prioritize. This is paradoxical, as the higher the role the lower chance for a plant to disappear from the GON [23]. With the 
current degree of globalization inefficient plants can no longer survive, even in distant local markets.

This paper will explore the application of Ferdows's model for the analysis of strategic plant roles in a GON and extend the scope of this model by discuss a framework for deploying an improvement roadmap, which facilitates a gradual upgrade of the strategic role of a plant within a GON.

\section{$2 \quad$ Literature Review}

In recent years the competitive environment has been characterized by a highly dynamic macro economical context and a global competitive landscape. In this environment, the internationalisation of operations has become a common trend for companies and this has further confirmed the necessity for strategies that continuously enable the renewal of organisational capabilities to adapt to this global competitive environment.

In this context, building and managing a GON is widely recognised as one of the most important challenges within international operations management [5],[37-38]. Evolving from an independently managed (or with lower interaction) plant network to a coordinated manufacturing network allows benefiting from the synergy among the plants [24],[39] by improving cost and delivery performance and enhancing the learning curve from the experiences of partners in the network [8]. However, the process and practice to optimise the overall performance of the operations network is still not well understood [40].

A common internationalisation approach, which looks for short-term cost reduction and competitiveness, is the establishment and management of foreign factories to benefit only from tariff and trade concessions, cheap labour, capital subsidies, and reduced logistics costs. Therefore, a limited range of work, responsibilities, network participation and resources are assigned to those factories [5]. Other companies demand much more from their foreign factories and, as a result, try to get much more out of them. This approach provides not only access to the already mentioned cost oriented incentives, but also a globally distributed manufacturing network with much higher proximity to potential regions, with close access to customers, suppliers, or specifically skilled, talented and motivated workforce. Those factories have a wider range of responsibilities and network interaction beyond a mere production work, as e.g. product or process engineering, purchasing decisions, after-sales service, etc. [4].

The questions that still remains unanswered is how to deploy the operations strategy in a multi-location GON and in particular how to balance the different competences and responsibilities of different plants within the network, taking into account that the each plant could assume different strategic responsibilities for themselves or for the whole GON.

The operations strategy is defined as the total standard of decisions that mould the long term capacities of any kind of operation and their contribution for the general business strategy through the reconciliation of the market requirements with the operations resources [7]. This operations strategy should in fact be reflected in the operations network design, which basically is about where to locate your supply sources and manufacturing and distribution operations, as well as the deployment of such operations, 
i.e. who should be supplying whom or the facility planning. It also arises when facing a rationalisation or restructuring an existing network [6].

Therefore, evolving from an independent managed (or with lower interaction) plant network to a coordinated manufacturing network allows to benefit from the synergy among the plants, to improve cost and delivery performance, and to enhance the learning curve from the experiences of network partners [8].

If managers do not consider manufacturing to be a source of competitive advantage, they are likely to establish foreign factories with a narrow strategic scope. In contrast, if managers regard manufacturing as a major source of competitive advantage, then the foreign plants will reward the company in the form of higher market share and greater profits [5].

The operations management literature has several models which cope with the supply chain analysis and performance (see a list of models e.g. in [1],[9]), but only few widen their scope from a supply chain perspective to an entire value chain approach - as defined by Porter [10]. Ferdows [4-5] implicitly covers the value chain and the international manufacturing network idea, especially when introducing the "lead plant" concept: it would be a plant contributing to the company's strategy by e.g. developing capabilities as new processes, products or technologies, or local skills, contact to end customers, suppliers, etc. These capabilities would be shared with other plants in the network.

However, despite of being reference model which is gaining academic recognition in the international operations field, as e.g. [1],[6],[11-15], there are still few evidences of empirical testing of Ferdows' model [6] - even when this model is easily recognisable in practice for executives.

The question that arises is how to deploy the operations strategy in a multi-location GON, i.e. how to balance the different competences and responsibilities along the different factories or facilities, taking into account that the different units of the GON could assume different strategic responsibilities for themselves or for the whole GON.

The intended strategy formulation and deployment is in fact a changing and adaptive exercise for the company: therefore the operations strategy and -by extension- the international manufacturing network design should integrate dynamic capabilities evaluation [16] as happens in any restructuring of a operations network.

These dynamic capabilities are defined by Teece et al [17] as "the ability to achieve new forms of competitive advantage to emphasise two key aspects that were not the main focus of attention in previous strategy perspectives. The term "dynamic" refers to the capacity to renew competences so as to achieve congruence with the changing business environment. The term "capabilities" emphasises the key role of strategic management in appropriately adapting, integrating and reconfiguring internal and external organisational skills, resources and functional competences to match the requirements of a changing environment".

Thus, the new paradigm in global operations strategy context is that if a company should adapt its operations to be as efficient and effective as possible, then there must be continuous reconfiguration of the manufacturing systems and the new proposal should consider the ability to be modified in the near future. The concept of Reconfigurable Manufacturing System (RMS) has posed salient inspiration for satisfying the aforementioned requirements: RMS was initially defined by [18] as "a machining system designed at the outset for rapid change in structure, as well as in hardware and 
software aspects, in order to quickly adjust production capacity and functionality within a part family in response to sudden changes in market or in regulatory requirements". The same principles can be easily applied to other system, as e.g. an operations network.

\section{$3 \quad$ Research Questions and Methodology}

The literature review confirms [3],[19] that in order to build and manage integrated GON could be the upcoming challenge for the operations management. Anyway the existing literature about how to design/restructure a GON is short and the study areas are dispersed [1],[20]. Furthermore the operations management literature has several models which cope with a supply chain analysis (SC) and performance (see [1] or [9]) but only few widen their scope from a SC perspective to an entire value chain approach -being the "Manufacturing Value Chain" [21] an interesting perspective that deserves attention.

Besides, the strategic factory role deployment to the operative level of sourcing, production and distribution has not been explicitly developed [6],[22]. Therefore any attempt to design/restructure a GON is difficult to put into practice, as the factory role concept is complex to formulate, deploy and prioritize. This is paradoxical, as the higher the role the lower chance for a plant to disappear from the GON [23].

Additionally two aspects related to GON need more research: 1) The understanding how to coordinate the operations of individual production units within a GON [22]: the network coordination itself can be a competitive advantage source [25]. 2) Diversified companies with different manufacturing networks (for different product typology) and their interdependence [19].

Therefore, this paper will cover the empirical application of the Ferdows model and extends its application to define how to systematically upgrade a plant strategic role acting within a GON by weakness-based identification, i.e. far beyond the solely analysis of the current strategic role.

At this point, the research question to be answered is the following: how could a facility improve its role - taking into account the systematic nature of the operations network? Which is the network strategy for balancing the different roles within the network? How could a facility role be operationalized in order to analyze the current and the target state respectively the drivers?

The methodological framework used for this study was based on Constructive research theory. The Constructive research is an approach that aims to produce solutions to explicit problems and is closely related to the concept of innovative constructivism [34]. This approach produces an innovative solution, which is theoretically grounded, to a relevant practical problem. An essential component of constructive research is the generation of new learning and knowledge in the process of constructing the solution [35].

In order to test this proposition, a two phase research design based on the principles of Action Research (AR) was devised, i.e. a theory building and a theory testing phase. 
The objective of the theory-building phase was to define a methodology/guide that could be used by practitioners in real organisations to design and configure a new manufacturing network, aided by different purpose-tailored techniques.

In the theory-testing phase, the approach used was tested and the results of the implementation process are shown. AR is a variation of the Case Study, where both researcher and client are actively engaged in solving a client-initiated project dealing with a certain business problem [36].

\section{Framework Proposal for Assessing/Upgrading Factory Roles}

If the factory competences are not enforced in order to get an upgraded strategic role, usually the less successful plans may disappear from the map due to competitive pressure to reduce costs and concentrate the production volume in a smaller number of plants [26]. Therefore companies should redesign and reconfigure the supply chain multisite network - either from a global (top down or network approach) or partial (bottom-up or production unit approach) initiative.

The proposed framework related to the strategic factory role is called Akondia and is part of the GLOBOPE global framework. It aims to facilitate the practical usage of the Ferdows' model respectively extends the Ferdows's model application by defining how to upgrade a plant strategic role within the framework of a GON, i.e. far beyond the solely analysis of the current strategic role.

The framework bases on an evaluation of the current value chain status, utilizes this competitive position status for assigning a strategic role and finally can be applied for deploying an improvement roadmap to get other facility role. Depending on the analysis scope, the Akondia Framework is able to contribute to the sustainability of the network (by identifying the strengths of each network unit and prioritising the assignment/development of competences in the network perspective) or of the individual units (supporting the upgrade to a more attractive facility role).

The factory role, as originally defined by Ferdows, implicitly covers functions which are over a manufacturing facility, i.e. aspects within a GON which are not only part of a Supply Chain but of the Value Chain (especially in the "lead plant" concept).

The Akondia framework establishes its roots for the factory role assessment therefore in the Value Chain concept defined by Porter [10]. Based on this Value Chain definition, the framework has been initially created by defining 6 main analysis fields: 1) Markets and customers, 2) Suppliers, 3) Internal Operations, 4) HR Management, 5) Technology Management and 6) Socio-political and regulatory. The 6 fields are mentioned by Ferdows in the different generic factory roles.

The framework has been developed in two analysis levels: 1) The first level should go through a "macro" perspective along the 6 main analysis fields. 2) A second detailed and separated "micro" approach per field can be utilised (e.g. Benchmark models for the analysis field, as SCM SCOR Model or Lean Production applications).

The first analysis level aims to provide a strategic facility profile or competitive position as an output, which later could be compared to the generic roles defined by Ferdows. In order to systematize the analysis, a questionnaire for different competences has been developed: 38 questions related to the 6 analysis fields. Each question assesses a competence, which is evaluated in two dimensions: 1) level of influence of 
the factory to develop the competence (e.g. is the factory able to select its strategic suppliers or is a central decision? Has the factory any influence in the new product technologies or is it developed by other central functions or competence centres?); and 2) current competence level.

The Akondia framework has 3 main clear stages in its application. 1) A first analysis of the current competitive position of the facility (strategic profile), 2) a second step which finds out the affinity of the strategic profile to the generic strategic roles of Ferdows and 3) a final stage, where the improvement/upgrade efforts are identified and prioritized.

The first step is therefore based on the questionnaire. When fulfilling it, there is a competitive position evaluation as an output, which already provides a first overview of the competence level per analysis field. The main conclusion coming out from this competitive position is an overview of the strengths and weaknesses of each analysed facility, showing the evaluated level per competence. An interesting extension of this analysis is its usage to compare the internal assessment (management of the facility) and the external view of e.g. Business Unit or Headquarters.

The second step of the Akondia framework is an analytical phase to be able to convert the competitive position of a facility into a Ferdows strategic role. The key element of this step is to be able to model each of the 6 strategic roles of Ferdows in the questionnaire. The authors have developed generic competitive positions (strategic profiles) for each and all of the Ferdows roles and contrasted them extensively via Delphi-panels. Denote anyhow that this evaluation could vary depending on e.g. sector, size of the company, business unit or product range, or company strategy.

The comparison of the generic competitive positions with the results of the evaluated questionnaire gives plenty of different data treatment possibilities. In their analysis, the authors propose a model to quantitatively measure the affinity of a facility to the given roles. In order to finalise the second step, the most suitable graphical presentation is to summarise the whole analysis by utilizing the Ferdows's model and placing each of the analysed facilities. It can be easily done based on the quantitative affinity model already described.

The third step of the Akondia framework is focused on how to get another role for any analysed facility (usually it should mean a more valuable). In order to make it more systematically, it is recommended to prioritise the effort for achieving the new role status. It has two main working axes: 1) Strengthen the current facility role. 2) Develop improvement roadmap for achieving a new facility role. For strengthening the current facility role, it is necessary to know the weakest competences; anyhow, the reader should come back to the first step of the framework and remind that the utilised questionnaire was scored on two dimension: the competence level and the additionally the influence level of the facility in the competence.

It is logical to assume that the higher the influence level on a given competence, the easier to improve its level. The Akondia framework proposes a first strengthening of the current strategic role based on a periodization matrix. This matrix shows graphically each of the 38 assessed competences in the questionnaire: the Y-Axis shows the level of each competence, while the $\mathrm{X}$-Axis provides the influence of a given facility for the assessed competence. Several graphical alternatives for a quickscan of the fields can be developed by cross-matching influence/competence levels. 
After strengthening the current competitive position by a focused improvement in competences where the influence is high, any facility could be suitable to develop a strategic role upgrade roadmap. Using the generic competitive positions (or strategic profile) for the strategic roles of Ferdows, a stepwise middle/long-term roadmap can be deployed. The authors recommend a deployment based on the 6 analysis field, balancing the current competence level, the influence level and the effort to achieve the required level (e.g. providing more influence to a facility by giving new responsibilities). These role changes could in fact imply organizational decisions or reassignment of responsibilities.

Any detailed improvement roadmap per field should have a second-level analysis and detailed deployment in the operative level -.e.g. for manufacturing facilities/operations network the "Suppliers" or "Operations Management" fields are key elements that could be improved by Benchmark models.

\section{Case Study: Data Collection and Theory Testing}

The testing phase of the Akondia framework was developed under Action-Research (AR) principles. AR is a generic term, which covers many forms of action-oriented research that focuses on deriving knowledge through action as opposed to positivist methods that aim to create universal knowledge [30-31] that satisfy scientific precepts, e.g. repeatability and unbiased observation. AR is defined as "a participatory process concerned with developing practical knowing in the pursuit of worthwhile human purposes. It seeks to bring together action and reflection, theory and practical solutions to issues of pressing concern to people" [32].

The Akondia framework was applied to a GON (18 plants in 7 countries) of a worldwide operating white-goods corporation dedicated to the design, production and distribution., which posted above 8 billion Euros in 2009 and is one of the global leading companies in the sector. The company has over 40 factories operating in Europe, the USA, Latin America and Asia, with a workforce numbering with approx. 40,000 people. The final result and score has been extensively checked with a Delphi panel (Factory Management Team, Headquarters) to reinforce the validity of the results [27-28].

\section{Conclusions}

The framework goes beyond the supply chain perspective models [22] and arises the necessity to be more specific/extend topics from the value chain that also influence the strategic factory role (e.g. product/process innovation, strategic supplier management) and the absence of assessment regarding the original contribution of lead factories in the network -i.e. for new topics the rest of factories profit themselves from the experiences in lead factories, as e.g. new product platform launch.

Regarding the application of the Akondia framework, the main conclusions are:

1) It serves as analysis tool for assessing the strategic plant role; 2) It helps prioritising the improvement aspects for changing the factory role and 3) It covers the entire factory complexity, i.e. not only operations but also the value chain aspects 
(e.g. product development, strategic purchasing). 4) The Akondia framework is an analysis and improvement tool for facilities which is able to cope with the 3 generic business strategies: operational excellence, product leadership and customer intimacy - as defined by Porter [8] and Kaplan and Norton [33]. Former attempts to model the Ferdows model were narrowed in their scope, due to the fact the unique generic business strategy that was properly assess was the "Operational Excellence" [22].

The case study provides: 1) New empirical application of the Ferdows' model;

2) Confirms that the framework can be broken down to model each factory role into operational aspects; 3) One of the first multi-product network assessment and possible interaction fields and 4) clear picture about how to utilise value-chain based models for analysing and improving any GON.

\section{References}

1. Corti, D., Egaña, M.M., Errasti, A.: Challenges for off-shored operations: findings from a comparative multi-case study analysis of Italian and Spanish companies. In: Proceedings 16th Annual EurOMA Conference, Gothenburg (2009)

2. Shi, Y., Gregory, M.J.: International Manufacturing Networks-to develop global competitive capabilities. Journal of Operations Management 16, 195-214 (1998)

3. Ernst, D., Kim, L.: Global production networks. Knowledge Diffusion and Local Capability Formation 31(8/9), 1417-1429 (2002)

4. Ferdows, K.: Mapping international factory networks. In: Ferdows, K. (ed.) Managing International Manufacturing, pp. 3-21. Elsevier Science Publishers, New York (1989)

5. Ferdows, K.: Making the most of foreign factories. Harvard Business Review, 73-88 (March-April 1997)

6. Vereecke, A., Van Dierdonck, R.: The Strategic Role of the Plant:Testing Ferdow's Model. International Journal of Operations \& Production Management 22(5) (2002)

7. Slack, N., Lewis, M.: Operations Strategy, 2nd edn. Prentice Hall, Upper Saddle River (2002)

8. Flaherty, T.: Coordinating international manufacturing and technology. In: Porter, M. (ed.). Harvard Business School Press (1986)

9. Netland, T., Alfnes, E., Fauske, H.: How mature is your supply chain? - A supply chain maturity assessment test. In: Proceedings of the 14th EurOMA Conference 2007, Ankara (2007)

10. Porter, M.E.: Competitive Advantage. The Free Press, New York (1985)

11. Fusco, J.P., Spring, M.: Flexibility vs. robust networks: the case of the Brazilian automotive sector. Integrated Manufacturing Systems 14(1), 26-35 (2003)

12. Meijboom, B., Voordijk, H.: Internacional operations and location decisions: a firm level approach. Tijdschrift Voor Economische En Sociale Geografie 94(4), 463-476 (2003)

13. Maritan, C.A., Brush, T.H., Karnani, A.G.: Plant roles and decision autonomy in multinational plant networks. Journal of Operations Management 22(5), 489-503 (2004)

14. Vereecke, A., Van Dierdonck, R., De Meyer, A.: A typology of plants in global manufacturing networks. Management Science 52(11), 1737-1750 (2006)

15. Feldmann, A., Olhager, J.: Plant roles and decision-making in manufacturing networks. In: Proceedings 16th Annual EurOMA Conference, Gothenburg (2009)

16. Sweeney, M., Cousens, A., Szwejczewski, M.: International manufacturing networks design - A proposed methodology. In: Proceedings of the 14th EurOMA Conference 2007, Ankara (2007) 
17. Teece, D.J., Pisano, G., Shuen, A.: Dynamic capabilities and strategic management. Strategic Management Journal 18(7), 509-533 (1997)

18. Koren, Y., Heisel, U., Jovane, F., Moriwaki, T., Pritschow, G., Ulsoy, H., Van Brussel, G.: Reconfigurable manufacturing systems. CIRP Annals-College International de Recherches Pour la Production 48(2), 527-540 (1999)

19. De Toni, A., Parussini, M.: International Manufacturing Networks: a literature review. In: 17th Conference EurOMA, Porto (2010)

20. Laiho, A., Blomqvist, M.: International Manufacturing Networks: a literature review. In: 17th Conference EurOMA, Porto (2010)

21. Singh Srai, J., Shi, Y.: Understanding China's Manufacturing Value Chain. University of Cambridge, Institute for Manufacturing Publishing, Cambridge (2008)

22. Mediavilla, M., Errasti, A.: Framework for assessing the current strategic plant role and deploying a roadmap for its upgrading. An empirical study within a global operations network. In: Proceedings of APMS 2010 Conference, Cuomo, Italy (2010)

23. Vereecke, A.: Network relations in multinational manufacturing companies. Flanders DC and Vlerick Leuven Gent Management School (2007)

24. Dubois, F.L., Toyne, B., Oliff, M.D.: International manufacturing strategies of U.S. multinationals: a conceptual framework based on a four-industry study. Journal of International Business Studies, Q2 24(2), 307-333 (1993)

25. Shi, Y., Gregory, M.: Emergence of global manufacturing virtual networks and establishment of new manufacturing infrastructure for faster innovation and firm growth. Production Planning \& Control 16(6), 621-631 (2005)

26. De Meyer, A., Vereecke, A.: International operations. In: Werner, M. (ed.) International Encyclopedia of Business and Management. Routledge, London (1996)

27. Linstone, H.A., Turoff, M.: The Delphi Method: Techniques and Applications. AddisonWesley, London (1975)

28. Turoff, M., Hiltz, S.: Computer based Delphi Processes, http://eies.njit.edu/ turoff/Papers/delphi3.html

29. Westbrook, R.: Action Research: a new paradigm for research in production and opérations management. Operations and Production Management 15(12), 6-20 (1995)

30. Coughlan, P., Coghlan, D.: Action research for operations management. International Journal of Operations and Production Management 22(2), 220-240 (2002)

31. Vignalli, C.: The marketing management process and heuristic devices: an action research investigation. Market Intelligence Plann. 21(4), 205-219 (2003)

32. Reason, P., Bradbury, H.: The Sage Handbook of Action Research: Participative Inquiry and Practice, 2nd edn. Sage Publications, Los Angeles (2008)

33. Kapland, R.S., Norton, D.P.: The Strategy-Focused Organization. Harvard Business School Press, Boston (2001)

34. Meredith, J.: Theory building through conceptual methods. International Journal of Operations and Production Management 13(5), 3-11 (1993)

35. Mendibil, K., Macbryde, J.C.: Designing effective team-based performance measurement systems: an integrated approach. International Journal of Production Planning and Control 16(2), 208-225 (2005)

36. Schein, E.H.: Process Consultation Revisited, Building the Helping Relationship. AddisonWesley, Reading (1999)

37. De Toni, A., Parussini, M.: International Manufacturing Networks: a literature review. In: Proceedings of 17th Conference EurOMA, Porto (2010) 
38. Netland, T.: Improvement programs in multinational manufacturing enterprises: a proposed theoretical framework and literature review. In: Proceedings of Euroma 2011 Conference, Cambridge, UK (2011)

39. Shi, Y., Gregory, M.: Emergence of global manufacturing virtual networks and establishment of new manufacturing infrastructure for faster innovation and firm growth. Production Planning \& Control 16(6), 621-631 (2005)

40. Rudberg, M.: Linking Competitive Priorities and Manufacturing Networks: A Manufacturing Strategy Perspective. International Journal of Manufacturing Technology and Management 6(1/2), 55-80 (2004) 